\title{
Expanded endoscopic endonasal surgery for advanced stage juvenile angiofibromas: a retrospective multi-center study*
}

\author{
Cristóbal Langdon', Philippe Herman², Benjamin Verillaud², Ricardo L. \\ Carrau $^{3}$, Daniel Prevedello ${ }^{3}$, Piero Nicolai ${ }^{4}$, Alberto Schreiber ${ }^{4}$, Giovanni \\ Padoan $^{5}$, Paolo Castelnuovo ${ }^{5}$, Manuel Bernal-Sprekelsen ${ }^{1}$ \\ 1 Department of Otolaryngology, Hospital Clínic, University of Barcelona Medical School, Barcelona, Spain \\ ${ }^{2}$ Hopital Lariboisière, ENT Department, AP-HP, and EA 7334 REMES Paris 7, France \\ ${ }^{3}$ Department of Otolaryngology-Head and Neck Surgery, Wexner Medical Center, The Ohio State University, Columbus, OH, USA \\ ${ }^{4}$ Department of Otorhinolaryngology-Head and Neck Surgery, University of Brescia, Brescia, Italy \\ ${ }^{5}$ Department of Otorhinolaryngology, University of Insubria, Varese, Italy
}

Rhinology 54: 239-246, 2016

DOl:10.4193/Rhino15.104

*Received for publication:

April 14, 2015

Accepted: December 30, 2015

\begin{abstract}
Objectives: Endoscopic resection has become an established surgical option for most juvenile nasopharyngeal angiofibromas (JNA). However, surgical management of JNA with intracranial extension remains challenging. This retrospective multicenter study reviews a series of patients with advanced stage JNA treated via endonasal/endoscopic approach.

Methods: The experience of five academic tertiary or quaternary care ORL-HNS Departments were included. Medical records of all patients operated for JNA staged as Radkowski stage IIIA or IIIB were reviewed. Main outcome measures included intraoperative blood loss, length of hospital stay, complication rate, and rate of persistence or recurrence.

Results: A total of 74 male patients with stages IIIA and IIIB were included. The mean age was 16.4 years and preoperative embolization was performed in 71 patients. The mean blood loss in 45 patients for whom the data was available was $1279.7 \mathrm{ml}$. The more anatomic subsites were involved, the higher the risk was of intraoperative bleeding. The mean follow-up for 54 out of 73 patients was 37.9 months. Patients with residual disease are significantly linked to involvement of combined (anterior-lateral and posterior) anatomic subsites and to a higher number of affected subsites. At last follow-up, all patients were asymptomatic and those with residual tissue displayed no imaging signs of growth.
\end{abstract}

Conclusions: This retrospective multicenter study supports the notion that expanded endonasal endoscopic approaches for advance staged JNA are a feasible option associated with good long-term results.

Key words: juvenile angiofibroma, endoscopic sinus surgery, maxillary artery, embolization, medial maxillectomy

\section{Introduction}

Juvenile angiofibroma (JNA) is a benign tumour associated with adolescent males between the ages of 9 to 19 years. In the USA, JNA accounts for $0.05 \%$ of head and neck tumours, with an incidence of 1:6000-1:16,000 (1,2). In the Middle East and in India the incidence seems significantly higher than in Europe ${ }^{(3)}$. JNAs may demonstrate an aggressive and destructive expansile growth pattern starting at the basisphenoid and sphenopalatine foramen. Its subsequent spread may reach the cranial cavity and orbit through preformed pathways such as orbital and skull base foramina and fissures ${ }^{(4)}$.

The ipsilateral maxillary artery provides their main vascular supply; however, vascularization from the contralateral maxillary artery may also occur ${ }^{(5)}$. Furthermore, in advanced cases, its vascularization may include branches from both external and internal carotid arteries. Reports about minimally invasive endoscopic resections for early stage angiofibromas (Radkowski 
stage I and II) were first published during the 1990s. These seminal reports demonstrated the feasibility of an endonasal endoscopic removal, while providing a similar recurrence rate to that of external approaches but with reduced risks and morbidity ${ }^{(6-12)}$. Improvements in surgical instrumentation, imaging, surgical navigation systems, and surgical techniques have enabled the endoscopic resection of Radkowski/Andrews stages IIC and IIIA tumours (12-19).

This retrospective multicenter study reviews a series of patients with advanced stage JNA in an attempt to assess the effectiveness of the endoscopic endonasal approach for this challenging tumour.

\section{Materials and methods \\ Patients}

The experience of five academic tertiary Otolaryngology-Head and Neck Surgery departments are included. Clinical and imaging records of all patients operated for JNAs, staged as Radkowski stage IIIA or IIIB, were reviewed and analyzed. JNAs with massive intracranial extension were not included in our study. Tumour extensions were scored based on a list of recognized growth patterns as follows: nasopharyngeal vault, pterygopalatine fossa, inferior orbital fissure, orbital apex, infratemporal fossa, temporal fossa, paratubal region, foramen ovale and rotundum, sphenoid sinus, base of pterygoid process, clivus, cavernous sinus, foramen lacerum, and optic canal ${ }^{(20,21)}$. The main outcome measures included intraoperative blood loss, length of hospital stay, complication rate, and rate of persistence or recurrence of disease.

\section{Statistical analysis}

Statistical analysis was performed using SPSS software version 16.0. The analysis was mainly descriptive. It aimed at illustrating and explaining the purpose of the discussion.

To calculate potential differences in the blood loss angiofibromas were grouped into anterior-lateral (nasopharyngeal vault, ethmoid, maxillary sinus, pterigopalatine fossa, foramen rotundum, infratemporal and temporal fossa, infraorbital fissure) and into anterior-lateral and posterior extensions (sphenoid, clivus, base of pterigoids, (inter-) pterigoid fossa, orbital apex and optic canal, cavernous sinus, foramina ovale and lacerum, paratubal extension). Assuming equal variances, statistical comparisons between both groups was performed with the t-Student test for independent variables, a significant difference being considered with a $\mathrm{p}<0.05$. A Pearson correlation was performed to study a potential relationship between the number of anatomic subsites involved and the amount of bleeding. In order to compare the rate of tumour persistence / relapse between both groups the $\chi^{2}$-method was employed for two qualitative variables (anterior / posterior and recurrence yes / no) and the t-Student test to as-

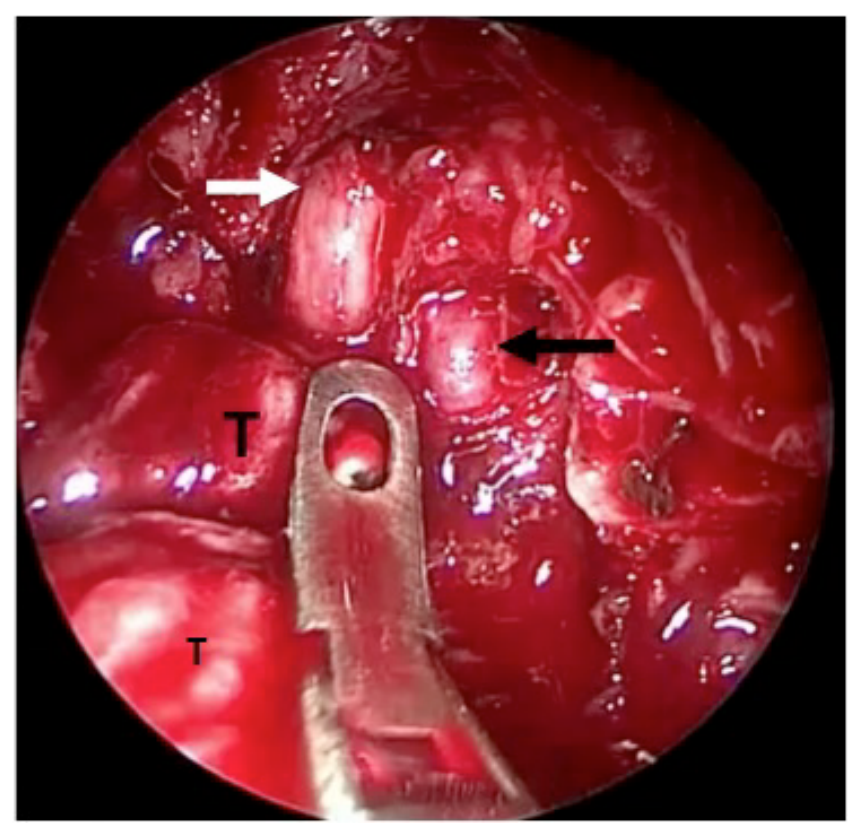

Figure 1. Intraoperative endoscopic view ( $0^{\circ}$ scope), infratemporal fossa is shown. Tumour $(T)$ retracted from the infratemporal fossa to the sinonasal space. White arrow, second branch of trigeminal nerve (V2); Black arrow, internal maxillary artery.

sess whether the rate of angiofibroma persistence was associated to the number of involved anatomic subsites.

\section{Operative technique}

Surgical technique varied among the different institutions and according to the size and extension of the lesion, but it also evolved with time even within each institution. Some basic principles could be identified: a centripetal approach and dissection around the tumour to avoid excessive bleeding, initial debulking or staging to gain space for instrumentation and a balanced approach to high risks areas weighing the benign nature of the tumour, symptoms, and age against potential risks. The order of the surgical steps enumerated in the following sentences may change depending on the extension of the JNA.

First, a large middle meatal antrostomy with partial or total resection of the middle turbinate was performed. The inferior turbinate was not removed unless the surgeon believed that removal was necessary to achieve wider access. Then the sphenopalatine foramen was identified to approach the sphenopalatine artery. The pterygomaxillary fissure is subsequently widened by removing the posterior and lateral wall of the maxillary sinus with rongeurs to improve the access laterally into the infratemporal fossa. Significant lateral extension of the lesion or a narrow nasal fossa may require a medial maxillectomy. In some cases extending far laterally into the maxillary sinus, a miniCaldwell-Luc trephination was made to introduce the scope for better visualization of the structures or a modified endoscopic 
Denker's, i.e. Sturman-Canfield, approach. The tumour is freed from its surroundings by blunt dissection, grasped and slowly retracted delivering it into the sinonasal field. At this point the maxillary artery may become visible and, if possible, the main trunk of the artery may be ligated or coagulated as far laterally (i.e. proximal) as possible (Figure 1). In two patients in whom the angiofibroma was attached to the masticatory muscles and the Bichat's fat, a lateral small antrostomy via a gingivobuccal incision was made to dissect these structures.

Anterior and posterior ethmoidectomies and a posterior septectomy of variable extension (dictated by the extent of the JNA and the geometry and dimensions of the sinonasal tract) further increased the space to adequately work around the lesion with the endoscopic instrumentation. These steps created a single cavity that merged the maxillary sinus, the nasal cavity, the pterygopalatine fossa, and the nasopharynx.

Tumour resection was completed drilling out all bony attachments of the tumour, mainly over the pterygoid process (with special attention to the vidian and round foramina), the basisphenoid and occasionally the vomer and the clivus. Drilling the basisphenoid and further areas of bony attachment (cancellous bone) with a diamond or hybrid burr after removing the tumour is important to reduce the risk of recurrence is important ${ }^{(22,23)}$. In cases of sphenoid sinus involvement, a cleavage plane was identified between the tumour and the sinus walls. It is of utmost importance to identify the optic nerve and the carotid artery to avoid accidental injury to these critical structures. The optic nerve can be tracked along the lateral wall of the sphenoid sinus coming anteriorly from the posterior ethmoid. The lateral optic-carotid recess, the vidian nerve, and the bony Eustachian tube do offer reliable landmarks to assess the parasellar, horizontal, and parapharyngeal aspects of the internal carotid artery. When the tumour had infiltrated and/or penetrated the floor of the sphenoid sinus, these components of the JNA were followed downwards and pushed to the nasopharynx. Feeders from the internal carotid artery were identified, cauterized and transected or packed.

A variety of unipolar and bipolar electrocautery and resection devices, as well as hemostatic agents, were progressively introduced and adopted into clinical use. Radiofrequency instruments, such as Coblator (ArthroCare ENT; Austin, TX, USA) or PlasmaCision (Olympus Global; Tokyo, Japan), have been embraced recently. These instruments provide the advantage of reducing the blood loss during the dissection and transection of the tumour. This enabled surgeons to evolve from the classical "en bloc" resection to a stepwise segmental removal, which progressively exposes all tumour extension; therefore, avoiding leaving tumour remnants in the middle of the surgical field. The addition of small polyvinyl alcohol particles (size 250-330 $\mu$ ) to the embolization paradigms helped to render the tumour further ischemic; thus, making it softer and easier to manipulate,
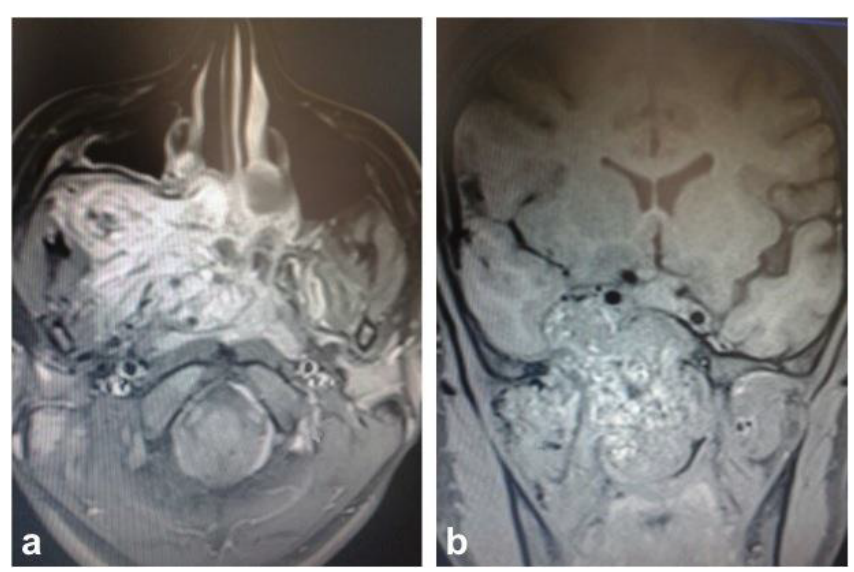

Figure 2. a) Axial T1 MRI sequence show a wide invasion of the infratemporal fossa with anterior extension up to bichat's fat pad. b) Coronal T1 MRI sequence showing the presence of prominent flow-voids that lead to a characteristic salt and pepper appearance, the tumour extends to the infratemporal and temporal fossa with medial displacement of the cavernous sinus.

and contributing to the reduction of blood loss. All these advances seemed to have catapulted an expansion of the indications for endonasal endoscopic approach in all institutions. The final steps were to deal with the cranial base extension of the tumour, especially those associated with the cavernous sinus, optic nerve, and carotid artery (Figure 2). Resection of these extensions is feasible, as the tumour does not invade these structures, but rather displaces them. Similarly, in our experience, JNA extensions into the middle cranial fossa could be detached from the dura with relative ease (with the exception of intradural extension, which is extremely rare and which purposefully was excluded in this study).

Follow-up of the patients varied among the centers, but all performed a complete nasal and nasopharyngeal endoscopy during visits. MRI was obtained post-operatively and at least yearly for three to five years to assess residual or recurrent tumour.

\section{Results}

\section{Demographics}

Seventy-four male patients with JNA staged as Radkowski IIIA (71.9\%) and IIIB (28.1\%) were operated via endonasal endoscopic approach. The average age was 16.4 years (range: 10-39 years; standard deviation 5.5). Seventy-one patients underwent preoperative angiography and embolization, and 14 (19.1\%) showed feeders from the internal carotid artery. Table 1 shows the demographics of patients who underwent endoscopic approaches for advanced JNA. The availability of outcomes data was variable among institutions. Therefore, the analysis was performed using the pertinent number of patients with the avai- 
Table 1. Demographics of JNA patients.

\begin{tabular}{|c|c|c|c|}
\hline & \multicolumn{2}{|c|}{ JNA stage } & \\
\hline & IIIA $(n=56)$ & IIIB $(n=18)$ & \\
\hline Age, years $(S D)$ & $16.5(5.9)$ & $16.1(4.5)$ & $p=0.704$ \\
\hline Blood Loss, ml (SD) & $\begin{array}{c}1279.7 \\
(2110.1)\end{array}$ & $n / d$ & \\
\hline Hospital stay, days (SD) & $5.3(3.2)$ & $6.1(2.9)$ & $p=0.056$ \\
\hline \multicolumn{4}{|l|}{ Complications } \\
\hline Hemorraghe & 0 & 1 & $\mathrm{n} / \mathrm{d}$ \\
\hline Nerve palsy* & 1 & 2 & $n / d$ \\
\hline Palatal insufficiency & 0 & 1 & $\mathrm{n} / \mathrm{d}$ \\
\hline $\begin{array}{l}\text { Recurrence time, } \\
\text { months (SD) }\end{array}$ & $38.5(14.8)$ & $22.5(12.1)$ & $p=0.31$ \\
\hline
\end{tabular}

* two patients trigeminal nerve (V2) anesthesia (one of those developed V2 neuralgia), one patient had a transient VI cranial nerve palsy.

lable information as the denominator.

\section{Hospital stay}

Mean hospital stay was 6.1 days (range 2-16; SD 3.6) for 47 cases registered. The time at hospital was one to three days for 14 cases (29.7\%), 4 to 7 days for 22 cases (46.8\%), and more than seven days for 11 cases (23.4\%). Five patients stayed hospitalized more than seven days due to extensive skull base repair (1), cavernous sinus and orbit infiltration (1), massive haemorrhage (2) and residual tissue (1). In the case of residual tissue the hospital stay was extended in one case with a stage IIIB JNA, as the intraoperative bleeding required blood transfusion and the postoperative recovery was slow.

\section{Blood loss and complications}

Data regarding intraoperative blood loss was available in 45 out of 74 patients, resulting in a mean blood loss of $1279.7 \mathrm{ml}$ (median was $600 \mathrm{ml}$; range $100-11000 \mathrm{ml}$; SD 2110.1). Two patients bled $8000 \mathrm{ml}$ and $11000 \mathrm{ml}$ respectively early in the series with lesions massively involving the greater wing of the sphenoid or the clivus. Bleeding was more related to venous than arterial bleeding. Considering these two patients as outliers, the mean blood loss for the remaining 43 cases was $956.9 \mathrm{ml}$ (range 100$6000 \mathrm{ml}$; SD 1169.3). In three patients the risk of embolization was considered too high by the neuroradiologists for various reasons (e.g.: additional vascular malformations, to strong blood supply from the internal carotid artery).

Tumours displaying exclusively anterior-lateral extensions $(\mathrm{n}=23)$ had a mean blood loss of $723.9 \mathrm{ml}$ (standard deviation $=587.1 \mathrm{ml}$ ) and angiofibromas with combined extensions (anterior-lateral and posterior) $(\mathrm{n}=20)$ a mean blood loss of
Table 2. Distribution of involved subsites ${ }^{*}\left(n=61^{\#)}\right.$.

\begin{tabular}{|c|c|}
\hline Subsites & (no. of cases) \\
\hline Pterygopalatine Fossa & 61 \\
\hline Nasopharyngeal vault & 56 \\
\hline Base of pterygoids & 47 \\
\hline Infratemporal fossa & 46 \\
\hline Sphenoid sinus & 46 \\
\hline Infraorbital fissure & 20 \\
\hline Cavernous sinus & 17 \\
\hline Foramen rotundum & 10 \\
\hline Ethmoid sinus & 9 \\
\hline Clivus & 9 \\
\hline Orbital apex & 9 \\
\hline Foramen lacerum & 9 \\
\hline Maxillary sinus & 8 \\
\hline Paratubal & 7 \\
\hline Base of pterigoids & 4 \\
\hline Temporal fossa & 3 \\
\hline Optic nerve canal & 2 \\
\hline Foramen ovale & 1 \\
\hline
\end{tabular}

*Multiple subsites involvement possible. " Data missing for 13 patients.

$1225 \mathrm{ml}$ (standard deviation $=1575.4 \mathrm{ml}$ ), the differences observed between both means did not reach statistical significance ( $p=0.164)$. Comparing the number of involved anatomic subsites the amount of blood loss correlates positively (Pearson: $r=0.376 ; p=0.013$ ) with increasing number of subsites. Table 3 shows extensions to the various anatomic subsites of $61 / 74$ type IIIA/B cases.

Regarding postoperative complications two patients had trigeminal nerve (V2) anesthesia, and one patient developed V2 neuralgia; another patient had a transient VI cranial nerve palsy; and one patient complained of palatal insufficiency (Table 1). All embolizations were performed through the external carotid artery. One case of blindness occurred because the material used for embolization migrated through a tumour neovascular shunt between the external and the internal carotid arteries. Secretory otitis media before or after surgery was not recorded.

\section{Follow-up and tumour relapse}

The mean follow-up for 54 out of 74 patients was 37.9 months (range 2-196 months; SD 39.6). CT or MRI evidenced residual disease 18 of 54 cases (33.3\%). Majority of the residual tumours were observed at the base of the pterygoids and basisphenoid. 
Table 3. Quality of life and diagnosis.

\begin{tabular}{|c|c|c|}
\hline Author & $\begin{array}{l}\text { Radkowski } \\
\text { Stage }\end{array}$ & Persistence / Recurrence \\
\hline $\begin{array}{l}\text { Jorissen et al. }{ }^{(28)} \\
(2000)\end{array}$ & $1 \mathrm{x} I I I A$ & $\begin{array}{l}4 \text { mo, regression after emboli- } \\
\text { zation }\end{array}$ \\
\hline $\begin{array}{l}\text { Roger et al. }{ }^{(12)} \\
(2002)\end{array}$ & $\begin{array}{l}9 x \text { IIIA (incl. } \\
7 \text { recurrence } \\
\text { after open } \\
\text { surgery) }\end{array}$ & $\begin{array}{l}1 \text { with residual tumor without } \\
\text { progression }\end{array}$ \\
\hline $\begin{array}{l}\text { Onerci et al. }{ }^{(15)} \\
(2003)\end{array}$ & $4 x \mid I I A$ & $\begin{array}{l}2 \text { with residual tumor without } \\
\text { progression. }\end{array}$ \\
\hline $\begin{array}{l}\text { Nicolai et al. }{ }^{(14)} \\
(2003)\end{array}$ & $3 x\|I I A, 1 x\| I B$ & all without tumor after $24 \mathrm{mo}$ \\
\hline $\begin{array}{l}\text { Hofmann et al. }{ }^{(19)} \\
\text { (2006) }\end{array}$ & $5 x I I I A$ & 1 recurrence \\
\hline $\begin{array}{l}\text { Sciaretta et al. }{ }^{(49)} \\
(2006)\end{array}$ & $1 \mathrm{x} \| \mathrm{IIA}$ & no recurrence \\
\hline $\begin{array}{l}\text { Tosun et al. }{ }^{(50)} \\
(2006)\end{array}$ & $2 x \| I I A$ & no recurrence \\
\hline $\begin{array}{l}\text { Ardehali et al. }{ }^{(48)} \\
(2009)\end{array}$ & $3 x\|I I A, 1 x\| I B$ & $\begin{array}{l}\text { 1x IIIA (primary); 1x IIIIA } \\
\text { (secondary) }\end{array}$ \\
\hline $\begin{array}{l}\text { Khalifa et al. }{ }^{(31)} \\
(2008)\end{array}$ & 16 IIIA & 2 recurrence at 4 and $7 \mathrm{mo}$ \\
\hline $\begin{array}{l}\text { Midilli et al. }{ }^{(51)} \\
\text { (2009) }\end{array}$ & IIIA & no recurrence \\
\hline $\begin{array}{l}\text { Cloutier et al. }{ }^{(24)} \\
\text { (2012) }\end{array}$ & $24 x$ IIIA & $\begin{array}{l}4 \text { recurrence and } 3 \text { residual tissue } \\
\text { without progression }\end{array}$ \\
\hline $\begin{array}{l}\text { Chan et al. }{ }^{(52)} \\
\text { (2014) }\end{array}$ & $5 x I I I A, 4 x I I I B$ & $\begin{array}{l}3 \text { with residual tissue on MRI, } \\
4 \text { with residual tumor without } \\
\text { progression }\end{array}$ \\
\hline
\end{tabular}

mo, months.

In one case there was residual tumour in the cavernous sinus and radiosurgery was indicated. Other two patients received radiotherapy and surgery respectively. These two patients, as well as the other 16 patients who were followed-up clinically, remain asymptomatic and continual MRI's show no growth of the residual tumours after a mean follow up of 35.6 months (range 3-82 months; SD 25.9). Table 3 shows a literature review about results after endoscopic removal of extended JNA.

Angiofibromas with anterior-lateral extensions and combined extensions (anterior-lateral and posterior) had 6/40 and 12/34 persistences respectively, with a statistically differences between both groups $(p=0.039)$. Also, the risk of angiofibroma persistence was significantly linked to a higher number of anatomic subsites involvement $(p=0.001)$.

\section{Discussion}

This retrospective multicenter analysis of 74 patients who underwent endoscopic endonasal resection of advanced-stage JNA demonstrates a paradigm shift in the surgical management of these tumours ${ }^{(24)}$. Transfacial approaches, like midfacial degloving, Lefort I osteotomies, lateral rhinotomy, or lateral infratemporal approaches, have been standard techniques for patients with intracranial invasion, optic nerve and/or internal carotid artery entrapment ${ }^{(25)}$, as well as for JNA with an infratemporal or temporal fossa involvement. This shift toward less invasive approaches reflects advances in techniques and technologies that have also transformed other surgical fields. However, from a practical point of view, the choice of the surgical approach is based on the surgeon's experience and training. The decision for the approach is based on basic concepts such as: adequate exposure of the tumour, ability to control the bleeding, avoidance of postoperative facial scars or deformity, and no interference with the growth of the facial skeleton.

Exposure of the tumour and hemostasis are a high priority and are often the justification for aggressive and potentially deforming transfacial approaches. These techniques enable a wide tumour exposure, but side effects may include scars, cosmetic deficits, hypoesthesia of V2 and V3, serous otitis media, and transient trismus after infratemporal approaches ${ }^{(26)}$. Endoscopic approaches use the natural corridors of the nasal cavity and paranasal sinuses, expanding the corridors to match the specific extension of the tumour. Haemostasis is best when following a centripetal approach, whenever possible; and has been greatly enhanced by advances in preoperative embolization and instrumentation (i.e. electrocautery, radiofrequency ablation). Increasing experience in expanded endoscopic sinus and skull base surgery has also allowed its use for more extended tumours ${ }^{(5)}$. Seminal reports showing successful endoscopic resections of JNAs were published in the 1990s, ${ }^{(7,9,10,27-29)}$. Since then, multiple series of endoscopic removal of JNA have shown results that are comparable to those obtained with open approaches $(5,12,30)$. Moreover, the use of angled endoscopes, coupled with high resolution cameras and monitors, proved to be especially useful to gain access to deep structures such as clivus, foramen lacerum, cavernous sinus or the infratemporal fossa where open approaches may fail to provide complete visualization ${ }^{(20,30,31)}$.

Proper patient selection is essential for the successful endoscopic management of JNA. In particular, it is paramount that the lateral extent of the tumour is accessible endoscopically. Others have tackled Radkowski stage IIC and limited stage IIIA JNA lesions with success ${ }^{(14,15,32)}$. Recently, Leong ${ }^{(33)}$ reported the feasibility of endoscopic surgery in a meta-analysis of 71 patients with JNA presenting intracranial involvement. Requirements include adequate surgical experience, proper instrumentation, preoperative embolization of the JNA, and the ability to convert to an open approach if needed.

In follow-up MRI of our cohort, 18 patients (33.3\%) between 11 and 18 years (mean 16.4 years), the images showed areas with contrast enhancement that were considered as having residual disease. All but two remain stable (no tumour growth and no 
symptoms) on long-term follow-up (median 31 months; range 3-82). It is unclear whether contrast enhancement alone may be considered tumour persistence or relapse, or part of the healing process (e.g. granulation tissue), especially when no growth can be detected and patients remain without symptoms ${ }^{(34)}$.

The majority of publications regarding endoscopic resection of early stage JNA report a low risk of recurrence ${ }^{(15,18,19)}$. Mann et al. ${ }^{(35)}$ published a recurrence rate of $6.6 \%$ in 15 patients with stage I and stage II disease. Similarly, Wormald and Van Hasselt ${ }^{(16)}$ had no local recurrence in seven patients (one Radkowski-stage I, two stage IIA, three stage IIB, and one stage IIC). These results have encouraged others to approach advanced JNA endoscopically. Nicolai et al. ${ }^{(14)}$ published a series of 15 patients treated endoscopically with a minimum 2-year follow-up. The cohort included four patients with advanced disease. Three extended to the infratemporal fossa and one also involved the inferior and superior orbital fissures. The fourth patient had intracranial extradural parasellar disease. None of the patients with advanced disease recurred during the follow-up period.

Onerci et al. ${ }^{(15)}$ divided a cohort of 12 patients into two groups. The first consisted of eight patients with tumours that were staged up to Radkowski stage IIC. Within this group there were no local recurrences after endoscopic resection. The second group consisted of four patients with stage IIIA tumours. All had limited intracranial penetration without dural invasion and medial to cavernous sinus. Two patients had complete resection of their tumours. The remaining two patients were left with residual intracranial disease that did not progress on serial MRI during the follow-up period. These authors suggested that a subtotal endoscopic removal of intracranial JNA with a "wait-and-see" policy might be preferable to a more aggressive craniofacial resection.

In a recent systematic review, Boghani et al. ${ }^{\left({ }^{(36)}\right.}$ found that purely endoscopic resection had a significantly lower rate of recurrence and/or residual tissue compared to both endoscopic assisted and open approaches. However, there was no difference in recurrence rate when they analyzed the individual patient data controlled for Radkowski/Sessions grading. Recurrence rates seem to be more related to the involvement of specific sites, such as the basisphenoid, anterior skull base, the infratemporal fossa, the cavernous sinus, the pterygoid process and pterygopalatine fossa, indicating that higher staged and, therefore, more extensive tumours tend to develop a higher rate of recurrence ${ }^{(37-39)}$. It has been shown, that drilling of the basisphenoid (cancellous bone around vidian canal) is critical to avoid recurrences in these areas ${ }^{(22)}$. Lloyd et al. ${ }^{(40)}$ found that $93 \%$ of recurrences occurred in patients with evidence of invasion (at CT or MRI) of the sphenoid diploe through the pterygoid canal.
Vascular supply to JNA is mainly from the maxillary artery, the ascending pharyngeal artery and the vidian artery ${ }^{(41)}$. However one must be aware of branches originating as "neovascularization" from the internal carotid artery when the tumour reaches the clivus or the cavernous sinus (medially or laterally). These vessels cannot be embolized safely, as the risk of a vascular complication is higher. Alternatively, direct intratumoural embolization under general anesthesia has been proposed for such cases, although a higher risk of complications has been reported ${ }^{(42)}$ and it has been formally contraindicated by some ${ }^{(10)}$.

Preoperative embolization provides a $60-70 \%$ reduction of the intraoperative bleeding and the need for blood transfusions ${ }^{(43)}$. When both external carotid artery systems are involved in the vascular supply, some have suggested to embolize both maxillary arteries ${ }^{(5)}$ to prevent the formation of an alternative vascular supply. Generally, angiography with embolization is performed 24-48 hours before surgery. However, when using resorbable materials, the interval should not exceed 48 hours because the arteries may recanalize ${ }^{(44)}$.

Snyderman et al. ${ }^{(21)}$ developed a staging system based on the residual vascularity from the internal carotid artery after preoperative embolization. They show a strong correlation between residual vascularity, skull base erosion, and intracranial involvement with blood loss, requirement for multiple procedures, and residual or recurrent tumour. In our series, all cases with residual tissue postoperatively had an involvement of the above-mentioned structures especially at the base of the pterygoid process and the sphenoid sinus.

Another important point regarding recurrences is the differentiation of true new tumour growth from asymptomatic, non-growing residual tumour tissue ${ }^{(45)}$. Small tumour remnants or tissue enhancement detected on MRI in asymptomatic patients may undergo involution after time ${ }^{(20,43,45)}$. Therefore, we do not see an indication for a revision surgery for intracranial remnants unless there is measurable tumour growth or new symptoms.

In our hands, tumour fragmentation ("piece-meal resection") using a radiofrequency device seemed helpful to progressively assess the extension. For larger tumour extensions with lateral extension into the infratemporal involvement, Khalifa and Ragab ${ }^{(31)}$ proposed an endoscopic assisted antral window approach. This enables the dissection of the tumour from the masticator muscles and the Bichats' fat and it was used in two cases. Hackmann et al. ${ }^{(5)}$ also presented endoscopic-assisted approaches in six cases in which a surgical incision was combined with endoscopy.

Blood loss during endoscopic removal is variable and generally is associated with the embolization and the stage of the 
JNA ${ }^{(15,34)}$. Glad et al. ${ }^{(43)}$ showed that embolization significantly decreased the intraoperative blood loss, from a mean of $650 \mathrm{ml}$ in the embolized group to $1200 \mathrm{ml}$ in the non-embolized group $(p<0.05)$; thus, reducing the need for perioperative blood transfusion $(p<0.005)$. Nicolai et al. ${ }^{(14)}$ suggested that the amount of blood loss is intimately linked to the quality of the embolization and to the tumour volume / extension. This latter point has being confirmed by Önerci ${ }^{(15)}$. Two studies ${ }^{(47,48)}$ compared the blood loss between endoscopic and open approaches. Although it seemed to be lower in the endoscopic surgery and in early stage tumours, one should consider that larger tumours were more frequently operated through an open approach (i.e. stages I and II were mainly operated endoscopically). In series comparing blood loss between endoscopic and open JA removal, the mean blood loss was lower in the endoscopic approaches ${ }^{(38,47)}$, and in lower staged tumours ${ }^{(47)}$. As previously mentioned, a selection bias has to be considered, as larger tumours were more frequently addressed by an open approach, while smaller tumours were mainly operated on endoscopically. In our series, we experienced a mean blood loss of $1279.7 \mathrm{~mL}$ (median blood loss of $600 \mathrm{ml}$ ), which is below the average of blood loss for open approaches of advanced stage JNA.

Two outliers showed an increased intraoperative blood loss. The bleeding was identified as coming from the pterygoid or basilar plexus. Here, suction of a constant venous bleeding during surgery can be underestimated; therefore, the use of hemostatic agents is strongly recommended. In addition, a staged resection is gaining acceptance in such situations.

In order to assess whether particular tumour extensions might be associated with a higher blood loss we identified groups of antero-lateral and combined (antero-lateral and posterior) extensions. No statistical significant could be found when comparing the means of blood loss between JNA with antero-lateral and posterior extensions. However, the higher the number of subsites were involved, the higher was the blood loss (Pearson $p=0.013$ ). A weakness of our study is that data about the amount of bleeding was not retrievable in all cases.

Also, comparing both groups of JNA extension showed a statistical difference in the rate of persistence of juvenile angiofibromas $(p=0.039)$. The more anatomic subsites were involved, the higher resulted the probability of tumour persistence $(p=0.001)$. Besides intraoperative bleeding, other complications included trigeminal V2 neuralgia and a transient VI nerve palsy. Trigeminal V2 deficit resembles the rate of complications of open approaches, but in these cases the extension of the tumour had encased the nerve and to achieve local control of the disease it had to be remove.

\section{Conclusion}

This retrospective multicentre study supports that, in experienced hands, the expanded endoscopic approach for advance staged JNA (Radkowski IIIA and IIIB) is a feasible option with good long-term control of the disease. With a statistical significance, the amount of intraoperative bleeding goes parallely to the number of involved anatomic subsites. The rate of residual tumour is statistically linked to combining anterior-lateral and posterior anatomic subsites and also to the JNA involvement of a higher number of subsites. Residual intracranial tumour or persisting enhancement in the imaging can be followed closely for potential growth or the development of symptoms.

\section{Authorship contribution}

$\mathrm{CL}, \mathrm{BV}, \mathrm{RC}, \mathrm{AS}, \mathrm{GP}$ collected the data. $\mathrm{CL}$ and $\mathrm{MB}$ analyzed the data and wrote the manuscript; all co-authors contributed to drafting the manuscript or revised it critically.

\section{Conflict of interest}

All the authors declare no conflict of interest.

\section{References}

1. Gullane PJ, Davidson J, O'Dwyer T, Forte $\checkmark$. Juvenile angiofibroma: a review of the literature and a case series report. Laryngoscope 1992;102(8):928-33.

2. Patterson CN. Juvenile nasopharyngeal angiofibroma. Otolaryngol Clin North Am 1973;6(3):839-61.

3. Maran AG LV. Clinical rhinology. New York: Thieme Medical Publishers; 1990:94-8.

4. Chandler JR, Goulding R, Moskowitz L, Quencer RM. Nasopharyngeal angiofibromas: staging and management. Ann Otol Rhinol Laryngol 1984; 93(4 Pt 1): 322-9.

5. Hackman T, Snyderman CH, Carrau R, Vescan A, Kassam A. Juvenile nasopharyngeal angiofibroma: The expanded endonasal approach. Am J Rhinol Allergy 2009; 23(1):95-9.

6. Kamel RH. Transnasal endoscopic surgery in juvenile nasopharyngeal angiofibroma. J Laryngol Otol 1996;110(10):962-8.

7. Tseng HZ, Chao WY. Transnasal endoscopic approach for juvenile nasopharyngeal angiofibroma. Am J Otolaryngol 1997; 18(2):151-4.

8. Bernal-Sprekelsen M, Vázquez AA, Pueyo J, Carbonell Casasús J. Endoscopic resection of juvenile nasopharyngeal fibromas. HNO 1998; 46(2):172-4.

9. Mitskavich MT, Carrau RL, Snyderman $\mathrm{CH}_{\text {, }}$ Weissman JL, Fagan JJ. Intranasal endoscopic excision of a juvenile angiofibroma. Auris Nasus Larynx. 1998; 25(1):39-44.

10. Newlands SD, Weymuller EA. Endoscopic treatment of juvenile nasopharyngeal angiofibroma. Am J Rhinol 1999; 13(3):213-9.

11. Carrau RL, Snyderman CH, Kassam AB, Jungreis CA. Endoscopic and endoscopicassisted surgery for juvenile angiofibroma.
Laryngoscope 2001; 111(3):483-7.

12. Roger G, Tran Ba Huy P, Froehlich P, Van Den Abbeele T, Klossek JM, Serrano E et al. Exclusively endoscopic removal of juvenile nasopharyngeal angiofibroma: trends and limits. Arch Otolaryngol-Head Neck Surg 2002; 128(8):928-35

13. Bernal-Sprekelsen M, Massegur Solench $H$, Tomás Barberán M. Paediatric endoscopic sinus surgery (PESS): review of the indications. Rev Laryngol - Otol - Rhinol 2003; 124(3):145-50.

14. Nicolai P, Berlucchi M, Tomenzoli D, et al. Endoscopic surgery for juvenile angiofibroma: when and how. Laryngoscope 2003; 113(5):775-82.

15. Önerci TM, Yücel ÖT, Öğretmenoğlu O. Endoscopic surgery in treatment of juvenile nasopharyngeal angiofibroma. Int J Ped Otorhinolaryngol 2003; 67(11):1219-1225. 
16. Wormald PJ, Van Hasselt A. Endoscopic removal of juvenile angiofibromas. Otolaryngol Head Neck Surg 2003; 129(6):684-91.

17. Pasquini E, Sciarretta V, Frank G, Cantaroni C, Modugno GC, Mazzatenta D et al. Endoscopic treatment of benign tumours of the nose and paranasal sinuses. Otolaryngol Head Neck Surg 2004; 131(3):180-6.

18. Pryor SG, Moore EJ, Kasperbauer JL. Endoscopic versus traditional approaches for excision of juvenile nasopharyngeal angiofibroma. Laryngoscope 2005; 115(7):1201-7.

19. Hofmann $T$, Bernal-Sprekelsen M, Koele W, Reittner $\mathrm{P}$, Klein $\mathrm{E}$, Stammberger $\mathrm{H}$. Endoscopic resection of juvenile angiofibromas-long term results. Rhinology 2005 43(4):282-9.

20. Herman P, Lot G, Chapot R, Salvan D, Tran Ba Huy P. Long-term follow-up of juvenile nasopharyngeal angiofibromas: analysis of recurrences. Laryngoscope 1999:109(1):140-7.

21. Snyderman CH, Pant H, Carrau RL, Gardner P. A new endoscopic staging system for angiofibromas. Arch Otolaryngol Head Neck Surg 2010; 136(6):588-94.

22. Howard DJ, Lloyd G, Lund V. Recurrence and its avoidance in juvenile angiofibroma. Laryngoscope 2001; 111(9):1509-11.

23. Sarria R, Capitán A, Sprekelsen C, Viviente E, Cuervo G, Ferrán A. Endoscopic surgery of nasopharyngeal angiofibroma by double embolization. Acta Otorrinolaringol Esp 2000: 51(3):259-62

24. Cloutier $T$, Pons $Y$, Blancal JP, Sauvaget $E$, Kania R, Bresson D et al. Juvenile nasopharyngeal angiofibroma: does the external approach still make sense? Otolaryngol Head Neck Surg 2012; 147(5):958-63.

25. Donald PJ, Enepikedes D, Boggan J. Giant juvenile nasopharyngeal angiofibroma: management by skull-base surgery. Arch Otolaryngol Head Neck Surg 2004; 130(7):882-6.

26. Browne JD, Jacob SL. Temporal approach for resection of juvenile nasopharyngeal angiofibromas. Laryngoscope 2000; 110(8):1287-93.

27. Anderhuber $W$, Stammberger $H$, Walch $C$, Fock C, Regauer S, Luxenberger W, et al. Rigid endoscopy in minimally invasive therapy of tumours of the paranasal sinuses and skull base. Minimally Invasive Therapy \& Allied Technologies 1999; 8(1):25-32.

28. Jorissen M, Eloy P, Rombaux P, Bachert C, Daele J. Endoscopic sinus surgery for juvenile nasopharyngeal angiofibroma. Acta Oto-Rhino Laryngol Belg 2000; 54(2):201-19.

29. Kamel RH. Transnasal endoscopic surgery in juvenile nasopharyngeal angiofibroma. Laryngol Otol 1996; 110(10):962-8.

30. Gupta a K, Rajiniganth MG. Endoscopic approach to juvenile nasopharyngeal angiofibroma: our experience at a tertiary care centre. J Laryngol Otol 2008; 122(11):1185-
9.

31. Khalifa MA, Ragab SM. Endoscopic assisted antral window approach for type III nasopharyngeal angiofibroma with infratemporal fossa extension. Int J Ped Otorhinolaryngol 2008; 72(12):1855-60

32. Schick B, El Rahman el Tahan A, Brors D, Kahle G, Draf W. Experiences with endonasal surgery in angiofibroma. Rhinology 1999; 37(2):80-5.

33. Leong SC. A systematic review of surgical outcomes for advanced juvenile nasopharyngeal angiofibroma with intracranial involvement. Laryngoscope 2013; 123(5):1125-31.

34. Lund VJ, Stammberger $H$, Nicolai $P_{\text {, }}$ Castelnuovo P, Beal T, Beham A et al.. European position paper on endoscopic management of tumours of the nose, paranasal sinuses and skull base. Rhinol Supp 2010; 1;(22):1-143.

35. Mann WJ, Jecker P, Amedee RG. Juvenile angiofibromas: changing surgical concept over the last 20 years. Laryngoscope 2004; 114(2):291-3

36. Boghani Z, Husain Q, Kanumuri VV, Khan MN, Sangrhi S, Liu JK et al. Juvenile nasopharyngeal angiofibroma; a systematic review and comparison of endoscopic endoscopic-assisted, and open resection in 1047 cases. Laryngoscope 2013 123(4):859-69

37. Tanvetyanon T, Qin D, Padhya T, Kapoor R, McCaffrey J, Trotti A. Survival outcomes of squamous cell carcinoma arising from sinonasal inverted papilloma: report of 6 cases with systematic review and pooled analysis. Am J Otolaryngol 2009; 30(1):3843.

38. Bleier BS, Kennedy DW, Palmer JN, Chiu AG, Bloom JD, O'Malley BW, Jr. Current management of juvenile nasopharyngeal angiofibroma: a tertiary center experience 19992007. Am J Rhinol Allergy 2009; 23(3):32830.

39. Beham A, Beham-Schmid C, Regauer S, Auböck L, Stammberger H. Nasopharyngeal angiofibroma: true neoplasm or vascular malformation? Adv Anat Pathol. 2000;7(1):36-46.

40. Lloyd G, Howard D, Phelps P, Cheesman A. Juvenile angiofibroma: the lessons of 20 years of modern imaging. J Laryngol Otol 1999; 113(2):127-34.

41. Draf W, Berghaus A. Tumouren und Pseudotumouren ("tumourähnliche Läsionen") der frontalen schädelbasis, augsehend von der Nase, den Nasennebenhöhlen und dem Nasenrachenraum (einschließlich der operativen Zugänge). Rhinochirurgisches Referat. Europ Arch Oto-Rhino-Laryngol 1993; Suppl 1993/1):106-86

42. Tranbahuy P, Borsik M, Herman P, Wassef M, Casasco A. Direct intratumoural embolisation of juvenile angiofibroma. Am J Otolaryngol 1994; 15(6):429-35

43. Glad H, Vainer B, Buchwald C, Petersen
BL, Theilgaard SA, Bonvin P, et al. Juvenile nasopharyngeal angiofibromas in Denmark 1981-2003: diagnosis, incidence, and treatment. Acta Oto-Laryngol 2007; 127(3):292-9.

44. De Vincentiis M, Gallo A, Minni A, Torri E, Tomassi R, Della RC. Preoperative embolisation in the treatment protocol for rhinopharyngeal angiofibroma: comparison of the effectiveness of various materials. Acta Otorhinolaryngol Ital 1997; 17(3):225-32

45. Jones GC, DeSanto LW, Bremer JW, Neel HB. Juvenile angiofibromas. Behavior and treatment of extensive and residual tumours. Arch Otolaryngol Head Neck Surg 1986; 112(11):1191-3.

46. Fagan JJ, Snyderman CH, Carrau RL, Janecka IP. Nasopharyngeal angiofibromas: selecting a surgical approach. Head Neck 1997 19(5):391-9.

47. Borghei P, Baradaranfar MH, Borghei SH, Sokhandon F. Transnasal endoscopic resection of juvenile nasopharyngeal angiofibroma without preoperative embolization. Ear Nose, Throat J 2006; 85(11):740-3, 746.

48. Ardehali MM, Samimi Ardestani S-H, Yazdani N, Goodarzi H, Bastaninejad S. Endoscopic approach for excision of juvenile nasopharyngeal angiofibroma: complications and outcomes. Am J Otolaryngol 2010; 31(5):343-9.

49. Sciarretta V, Pasquini E, Farneti G, Frank G, Mazzatenta D, Calbucci F. Endoscopic sinus surgery for the treatment of vascular tumors. Am J Rhinol. 2006 JulAug;20(4):426-31.

50. Tosun F, Ozer C, Gerek M, Yetiser S. Surgical approaches for nasopharyngeal angiofibroma: comparative analysis and current trends. J Craniofac Surg. 2006 Jan;17(1):1520

51. Midilli R, Karci B, Akyildiz S. Juvenile nasopharyngeal angiofibroma: analysis of 42 cases and important aspects of endoscopic approach. Int J Pediatr Otorhinolaryngol 2009 Mar;73(3):401-8

52. Chan KH, Gao D, Fernandez PG, Kingdom $T T$, Kumpe DA. Juvenile nasopharyngeal angiofibroma: vascular determinates for operative complications and tumor recurrence. Laryngoscope 2014 Mar;124(3):672-7.

Manuel Bernal-Sprekelsen, M.D.,

Ph.D.

Servicio de ORL, Hospital Clinic University of Barcelona Medical School

Barcelona

Villarroel, 170, Esc.8, 2A

08036 Barcelona

Spain

E-mail: mbernal@clinic.ub.es 